\title{
Article \\ Elderly Suffering from ST-Segment Elevation Myocardial Infarction-Results from a Database Analysis from Two Mediterranean Medical Centers
}

\author{
Leor Perl 1,2,*, Alfonso Franzé ${ }^{3}$ (D) Fabrizio D'Ascenzo ${ }^{3}$, Noa Golomb ${ }^{1,2}$, Amos Levi ${ }^{1,2}$, Hana Vaknin-Assa ${ }^{1,2}$, \\ Gabriel Greenberg ${ }^{1,2} \mathbb{D}$, Abid Assali ${ }^{2,4}$, Gaetano M. De Ferrari ${ }^{5}$ and Ran Kornowski ${ }^{1,2}$ (D)
}

1 Department of Cardiology, Rabin Medical Center-Beilinson Hospital, Petach Tikva 4941492, Israel; noagolomb@gmail.com (N.G.); amos.levi@gmail.com (A.L.); hana100niki@gmail.com (H.V.-A.); gabrigr75@gmail.com (G.G.); ran.kornowski@gmail.com (R.K.)

2 Sackler Faculty of Medicine, Tel Aviv University, Tel Aviv 69978, Israel; assali@clalit.org.il

3 Division of Cardiology, Department of Medical Sciences, Città della Salute e della Scienza, University of Turin, Corso Bramante 88, 10126 Turin, Italy; franze.alfonso@gmail.com (A.F.); fabrizio.dascenzo@gmail.com (F.D.)

4 Department of Cardiology, Meir Medical Center, Tchernichovsky St 59, Kfar-Saba 4428164, Israel

5 Department of Cardiology, Fondazione IRCCS Policlinico San Matteo, Viale Camillo Golgi 19, 27100 Pavia, Italy; gaetanomaria.deferrari@unito.it

* Correspondence: leorperl@gmail.com or leorper@clalit.org.il; Tel.: +972-3-9372251; Fax: +972-3-9372460

Citation: Perl, L.; Franzé, A.; D'Ascenzo, F.; Golomb, N.; Levi, A.; Vaknin-Assa, H.; Greenberg, G.; Assali, A.; De Ferrari, G.M.; Kornowski, R. Elderly Suffering from ST-Segment Elevation Myocardial Infarction-Results from a Database Analysis from Two Mediterranean Medical Centers. J. Clin. Med. 2021, 10, 2435. https://doi.org/10.3390/ jcm10112435

Academic Editor: Salvatore De Rosa

Received: 17 April 2021

Accepted: 27 May 2021

Published: 30 May 2021

Publisher's Note: MDPI stays neutral with regard to jurisdictional claims in published maps and institutional affiliations.

Copyright: (c) 2021 by the authors. Licensee MDPI, Basel, Switzerland. This article is an open access article distributed under the terms and conditions of the Creative Commons Attribution (CC BY) license (https:/ / creativecommons.org/licenses/by/ $4.0 /)$.

\begin{abstract}
Background: Little is known regarding primary percutaneous coronary intervention (pPCI) for ST-segment elevation myocardial infarction (STEMI) in the elderly. Methods: Data on 319 octogenarians, 641 septuagenarians, and 2451 younger patients was collected from an ongoing prospective registry of patients treated with pPCI for STEMI at two Mediterranean-area medical centers in 2009-2017. Results: More octogenarian patients were female (40.8 vs. 31.9 septuagenarians and $26.5 \%$ under $70 \mathrm{y}, p<0.01$ ), had hypertension (79.5 vs. 69.5 and $45.9 \%, p<0.01$ ), renal failure (32.5 vs. 20.1 and $5.2 \%, p<0.01$ ), and a lower left-ventricular ejection fraction (42.0 vs. 44.9 and $47.6 \%$, $p=0.012$ ). At 1 month and 3 years after intervention, mortality was higher in the octogenarian patients ( 12.2 vs. $7.9 \%, p=0.01$; and 36.7 vs. $23.1 \%, p<0.01$, respectively), with no significant differences in the rates of recurrent myocardial infarction, target vessel revascularization, coronary artery bypass surgery, and cardiovascular death. Following adjustment for confounders, 3-year mortality was significantly higher in the octogenarians (HR 3.89 vs. 3.19 for septuagenarians, $p<0.01$ ), but rates of major adverse cardiac events or cardiovascular death were not. Conclusions: Despite suffering from higher all-cause mortality, octogenarian patients treated with pPCI for STEMI do not suffer an increased risk of ischemic cardiac events relative to younger patients.
\end{abstract}

Keywords: octogenarians; elderly; myocardial infarction

\section{Introduction}

The general population of the developed world is gradually ageing, and the proportion of octogenarians is expected to triple by 2050 [1]. Cardiovascular disease poses a growing burden as age increases, and it remains the leading cause of morbidity and mortality in the elderly. Indeed, age is the strongest risk factor for the development of coronary heart disease [1-3]. In the United States, approximately one-third of deaths in the elderly each year can be attributed to acute coronary syndromes [2].

Compared to younger patients, the elderly present with more comorbidities and are at higher risk of mortality and complications following percutaneous coronary intervention (PCI) [4], especially those with acute coronary syndromes or ST-elevation myocardial infarction (STEMI) [5-13]. Furthermore, elderly patients are more likely to present with atypical symptoms, increasing the risk of delay in treatment or misdiagnosis [14,15]. Nevertheless, the benefit of revascularization in the elderly population is well established $[9,16-19]$, and 
PCI is associated with better outcomes and a lower rate of bleeding than fibrinolysis [20-22]. Both the European and American guidelines emphasize that there is no upper age limit for reperfusion, and in the elderly population, as in younger patients, an early invasive strategy is preferred [23,24].

The proportional representation of elderly patients in clinical trials assessing revascularization for STEMI is much lower than in routine clinical practice [25-27]. Therefore, information on the clinical characteristics and outcomes of octogenarians undergoing revascularization, particularly by means of primary PCI (pPCI), is limited. The aim of the present study was to examine the short- and long-term outcomes of octogenarian patients who were treated with pPCI for STEMI at two large Mediterranean-area tertiary medical centers.

\section{Materials and Methods}

\subsection{Patients and Setting}

The clinical data of consecutive patients presenting with STEMI and treated by pPCI at the Department of Cardiology, Rabin Medical Center, Israel, between January 2009 and December 2017 or the Department of Medical Sciences, University of Turin, Italy, between June 2015 and January 2017 were prospectively entered into a registry for purposes of monitoring patient-related parameters and clinical events. Patients included in this post hoc study were divided into octogenarian, septuagenarian, and younger than 70 years of age. Exclusion criteria were presentation with cardiogenic shock, treatment by thrombolysis, and ineligibility for a year-long dual antiplatelet regimen. The study was approved by the Institutional Review Boards of the two participating centers (study number RMC-3741 at the Rabin Medical Center and study number 0119191 at the Department of Medical Sciences, University of Turin).

\subsection{Interventional Procedure}

All patients provided explicit written informed consent before undergoing cardiac catheterization. Pretreatment consisted of aspirin and unfractionated heparin $(70 \mathrm{U} / \mathrm{kg})$; clopidogrel 300 or $600 \mathrm{mg}$, prasugrel $60 \mathrm{mg}$, or ticagrelor $180 \mathrm{mg}$ was administered as a loading dose before or immediately after PCI. The utilization of glycoprotein IIb/IIIa inhibitors and the choice of drug-eluting stent versus bare-metal stent were left to the discretion of the primary operator. All stents were implanted with moderate-to-high deployment pressure (14 to $18 \mathrm{~atm}$ ). All patients received dual antiplatelet therapy with aspirin $100 \mathrm{mg}$ daily and a P2Y12 inhibitor (clopidogrel, prasugrel, or ticagrelor) for at least 12 months after PCI.

\subsection{Study Endpoints}

Immediate and in-hospital clinical events were prospectively recorded in the institutional database. During follow-up, patients completed standardized questionnaires on clinical events at 6-month intervals either by telephone or in the outpatient clinic. When indicated, records from peripheral hospitals were acquired to verify the events. All events were further confirmed and adjudicated by the institutional clinical events adjudication committees comprising of three independent physicians. Survival status was assessed by municipal civil registries at 1 and 3 years.

Clinical outcomes included all-cause mortality and major adverse cardiac events (MACE), which comprised myocardial infarction (MI), target vessel revascularization (TVR), and coronary artery bypass surgery (CABG). Other endpoints were peri-procedural arrhythmias, vascular complications (periprocedural hematomas, retroperitoneal bleeding, pseudoaneurysms, arteriovenous fistula, arterial thrombosis, distal embolism, dissection, and transient limb ischemia), 30-day bleeding according to the thrombolysis in myocardial infarction (TIMI) classification, acute kidney injury (defined as a serum creatinine elevation $\geq 50 \%$ or $\geq 0.3 \mathrm{mg} / \mathrm{dL}$ from baseline in the first $72 \mathrm{~h}$ ), stent thrombosis, and cardiac death (defined as death occurring due to cardiovascular causes or cerebrovascular causes and 
any death without another known cause). Anemia was defined as hemoglobin levels lower than $13.0 \mathrm{~g} / \mathrm{dL}$ for men and $12.0 \mathrm{~g} / \mathrm{dL}$ for women. Renal failure at baseline was defined as glomerular filtration rate below $50 \mathrm{~mL} / \mathrm{min} / 1.73 \mathrm{~m}^{2}$ (calculated according to the Modification of Diet in Renal Disease formula). Findings were compared between patients younger than 70 years, septuagenarian, and octogenarian patients.

\subsection{Statistical Analysis}

Continuous data are summarized as mean and standard deviation (SD) or median and interquartile range (IQR), and categorical data as frequency (\%). Analysis of variance (ANOVA) was used to compare continuous variables between groups, and chi-square or Fisher's exact test was used for categorical variables. The normality of variable distributions was assessed using the Kolmogorov-Smirnov test. Time-to-event curves were constructed using the Kaplan-Meier method and compared using a log-rank test. In addition, competing risk analysis was performed, presented as cumulative incidence function. Cox regression analyses were performed to identify independent predictors of the primary end point. Effect sizes are presented as odds ratio and $95 \%$ confidence interval (CI). Stepwise variable selection of significant univariate predictors $(p<0.1)$ was used to identify variables for inclusion in the multivariate model. Multivariate logistic regression analysis was performed to determine independent predictors of the primary end point, accounting for known baseline cardiovascular risk differences. All statistical analyses were performed with IBM SPSS V.27 except for the competing risk analysis, which was performed with $\mathrm{R}$ V.4.0.0 software. A $p$ value of $<0.05$ was considered statistically significant.

\section{Results}

A total of 3411 patients were included in the STEMI registry at the time of the study: 2828 from Rabin Medical Center and 583 from the University of Turin Medical Center. Of these, 960 consecutive patients $(28.1 \%)$ were older than 70 years. There were 641 septuagenarians of mean age $75.3 \pm 2.8$ years, 319 octogenarians of mean age $85.5 \pm 3.6$ years, and 2451 patients younger than the age of 70 (mean age $55.8 \pm 8.7$ ). Baseline characteristics, procedural details, and quantitative coronary angiographic data were available for all of them.

The clinical and treatment-related characteristics of the different age groups are shown in Tables 1 and 2. The octogenarian group had a higher proportion of female patients, when compared with the septuagenarians and younger patients (40.8 vs. 31.9 and 26.5\%, respectively, $p<0.01$ ) and higher rates of diabetes (35.6 vs. 37.2 and $24.5 \%, p=0.04$ ), hypertension (79.5 vs. 69.5 and $45.9 \%, p<0.01$ ), previous CABG (7.1 vs. 4.1 and 2.5\%, $p<0.01$ ), renal failure (32.5 vs. 20.1 and 5.2\%, $p<0.01)$, previous CVA (12.9 vs. 13.6 and $3.6 \%, p=0.023)$, and peripheral artery disease (10.0 vs. 7.1 and $4.0 \%, p<0.01)$. However, mean body mass index was lower $(26.7 \pm 5.2$ vs. $27.2 \pm 5.6$ and $28.1 \pm 6.0, p=0.042)$. Older patients presented with a lower left-ventricular ejection fraction (42.0 vs. 44.9 and $47.6 \%, p=0.012$ ), and more had severely calcified (32.6 vs. 25.3 and $27.5 \%, p=0.021$ ) and bifurcation lesions ( 35.8 vs. 28.3 and $27.3 \%, p=0.011$ ). They were more often treated with clopidogrel (55.8 vs. 48.7 and $14.8 \%, p=0.039$ ) or intra-aortic balloon pump (5.5 vs. 6.1 and $2.9 \%, p=0.001)$, but not with drug-eluting stents ( 82.1 vs. 84.3 vs. $92.1 \%, p=0.014)$. There were no significant differences between the groups in rates of periprocedural complications, including vascular events, acute renal failure, and arrhythmias (Tables 1 and 2).

Outcome analyses showed that compared to the septuagenarian group and patients younger than 70 years of age, the octogenarians had a higher rate of all-cause death at 1 month (19.0 vs. 12.3 and $2.9 \%, p=0.01), 12$ months ( 27.4 vs. 19.3 and $4.7 \%, p<0.01)$, and 3 years after treatment (38.9 vs. 25.7 and 8.2\%, $p<0.01$ ) (Figure 1). At 3 years, there was no between-group difference in the rate of cardiovascular death (9.6 vs. 8.8 and $6.9 \%, p=0.12$ ); rates of recurrent MI, TVR, CABG, and MACE (Figures 1 and 2); or rate of stent thrombosis at 3 years ( 2.1 vs. 3.6 and $2.9 \%, p=0.13$ ). A competing risk analysis for the causes of death also showed differences in noncardiovascular and all-cause death, but not cardiovascular death (Figure 3). 

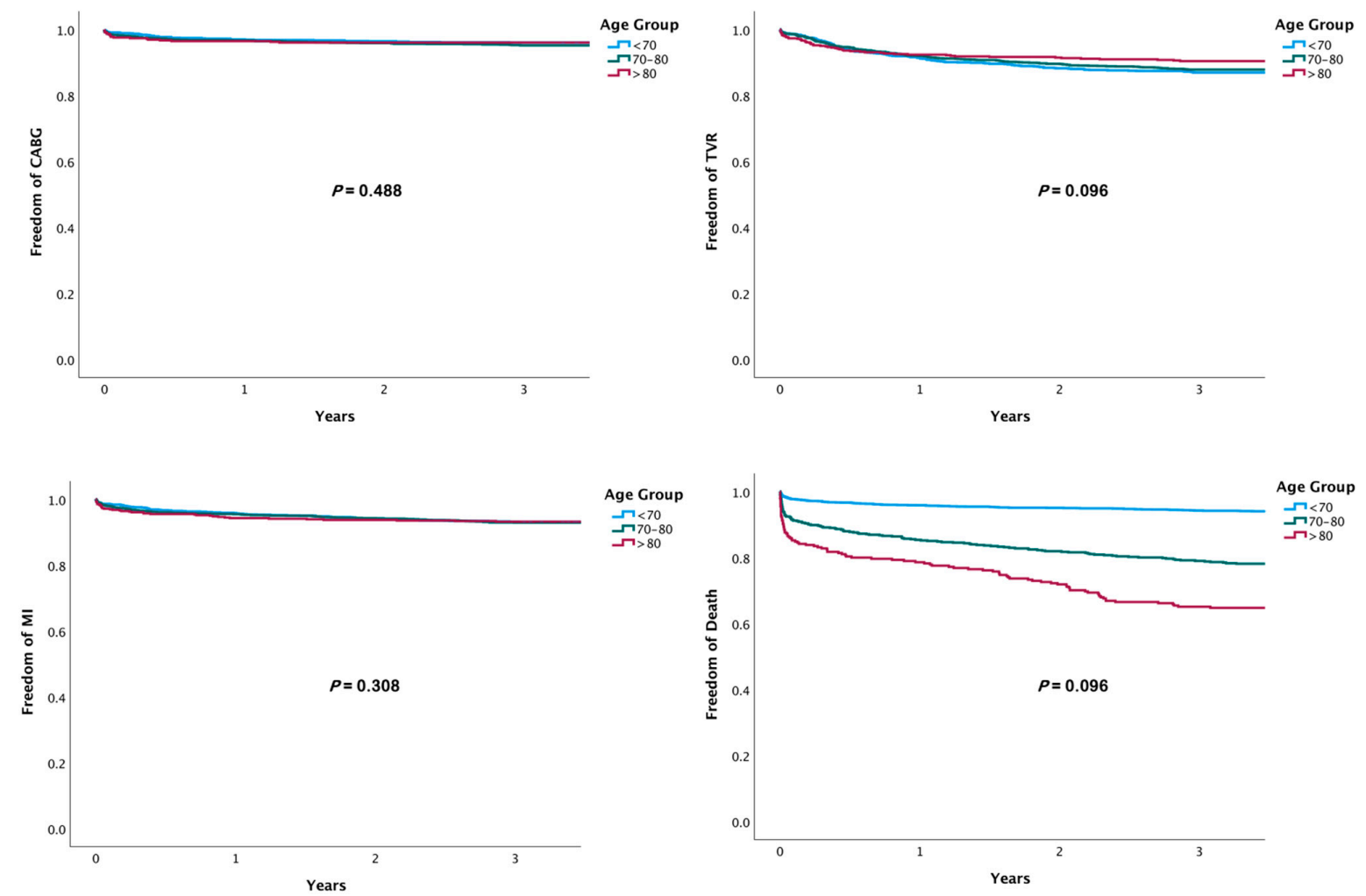

Figure 1. Kaplan-Meier curves of ischemic outcomes according to age.

Table 1. Baseline characteristics.

\begin{tabular}{|c|c|c|c|c|}
\hline Characteristic & $\begin{array}{c}80 y \text { and above } \\
(n=319)\end{array}$ & $\begin{array}{c}70-80 y \\
(n=641)\end{array}$ & $\begin{array}{l}\text { 70y and below } \\
(n=2451)\end{array}$ & $p$ Value \\
\hline Mean age (years) & $85.5 \pm 3.6$ & $75.3 \pm 2.8$ & $55.8 \pm 8.7$ & $<0.001$ \\
\hline Male (\%) & 59.2 & 68.1 & 73.5 & 0.040 \\
\hline BMI $\left(\mathrm{kg} / \mathrm{m}^{2}\right)$ & $26.7 \pm 5.2$ & $27.2 \pm 5.6$ & $28.1 \pm 6.0$ & 0.042 \\
\hline T2DM $(\%)$ & 35.6 & 37.2 & 24.5 & 0.040 \\
\hline Hypertension (\%) & 79.5 & 69.5 & 45.9 & $<0.001$ \\
\hline Hyperlipidemia (\%) & 53.2 & 52.3 & 54.9 & 0.478 \\
\hline \multicolumn{5}{|l|}{ Smoking (\%) } \\
\hline Active & 32.2 & 33.5 & 31.2 & \multirow{3}{*}{0.125} \\
\hline Past & 11.2 & 9.8 & 8.1 & \\
\hline Never & 56.6 & 56.7 & 60.7 & \\
\hline Anemia (\%) & 24.2 & 21.3 & 18.4 & 0.089 \\
\hline Previous PCI (\%) & 20.6 & 16.2 & 16.0 & 0.115 \\
\hline $\begin{array}{c}\text { Previous myocardial infarction } \\
(\%)\end{array}$ & 17.0 & 17.1 & 10.2 & 0.832 \\
\hline Previous CABG (\%) & 7.1 & 4.1 & 2.5 & $<0.001$ \\
\hline Renal failure (\%) & 32.5 & 20.1 & 5.2 & $<0.001$ \\
\hline Previous CVA (\%) & 12.9 & 13.6 & 3.6 & 0.023 \\
\hline Peripheral artery disease (\%) & 10.0 & 7.1 & 4.0 & $<0.001$ \\
\hline Aspirin $(\%)$ & 84.2 & 77.1 & 56.7 & $<0.001$ \\
\hline Statins (\%) & 73.2 & 70.2 & 49.5 & $<0.001$ \\
\hline Beta-blockers (\%) & 68.2 & 64.1 & 59.7 & 0.013 \\
\hline ACE inhibitors (\%) & 52.1 & 50.3 & 47.2 & 0.136 \\
\hline $\operatorname{LVEF}(\%)$ & $42.0 \pm 12.1$ & $44.9 \pm 11.9$ & $47.6 \pm 11.7$ & 0.012 \\
\hline $\operatorname{GFR}\left(\mathrm{mL} / \mathrm{min} / 1.73 \mathrm{~m}^{2}\right)$ & $81.3 \pm 19.1$ & $84.6 \pm 20.9$ & $86.6 \pm 22.3$ & 0.002 \\
\hline Hemoglobin $(\mathrm{g} / \mathrm{dL} \pm \mathrm{SD})$ & $12.1 \pm 2.1$ & $13.1 \pm 2.2$ & $13.5 \pm 2.6$ & 0.014 \\
\hline Platelets $\left(\times 10^{9} / \mathrm{L} . \pm \mathrm{SD}\right)$ & $182.2 \pm 45.1$ & $183.3 \pm 46.4$ & $183.5 \pm 50.1$ & 0.138 \\
\hline Glucose $(\mathrm{mg} / \mathrm{L} \pm \mathrm{SD})$ & $137.2 \pm 52.7$ & $133.1 \pm 49.6$ & $134.1 \pm 52.1$ & 0.241 \\
\hline Peak-CPK (mcg/L \pm SD) & $2085.7 \pm 331.3$ & $1986.5 \pm 323.0$ & $2123.7 \pm 325.8$ & 0.423 \\
\hline
\end{tabular}

BMI—body mass index, T2DM—diabetes mellitus, PCI—percutaneous coronary intervention, CABG—coronary artery bypass graft surgery, CVA-cerebrovascular accident, ACE - angiotensin converting enzyme, LVEF-left ventricular ejection fraction, GFR-glomerular filtration rate, $\mathrm{CPK}$ - creatine phosphokinase. 
Table 2. Procedural and in-hospital characteristics.

\begin{tabular}{|c|c|c|c|c|}
\hline Characteristic & $\begin{array}{c}80 y+ \\
(n=319)\end{array}$ & $\begin{array}{c}70-80 y \\
(n=641)\end{array}$ & $\begin{array}{c}70 y- \\
(n=2451)\end{array}$ & $p$ Value \\
\hline Median door-to-balloon time (IQR) & $1.09(0.2-4.5)$ & $1.04(0.3-4.2)$ & $1.03(0.2-4.1)$ & 0.301 \\
\hline Calcification (\%) & 32.6 & 25.3 & 27.5 & 0.021 \\
\hline Bifurcation lesions (\%) & 35.8 & 28.3 & 27.2 & 0.011 \\
\hline Mean number of affected vessels & $1.9 \pm 0.4$ & $2.1 \pm 0.5$ & $1.8 \pm 0.3$ & 0.828 \\
\hline Stenting $(\%)$ & 94.0 & 95.5 & 96.4 & 0.083 \\
\hline \multicolumn{5}{|l|}{ Culprit vessel (\%) } \\
\hline Left main artery & 4.5 & 4.6 & 5.1 & \multirow{5}{*}{0.542} \\
\hline Left anterior descending artery & 42.3 & 40.1 & 40.6 & \\
\hline Circumflex artery & 20.2 & 22.1 & 24.7 & \\
\hline Right coronary artery & 30.4 & 29.4 & 27.8 & \\
\hline Venous graft & 2.6 & 3.8 & 1.8 & \\
\hline DES (\%) & 82.1 & 84.3 & 92.1 & 0.014 \\
\hline Stent diameter $(\mathrm{mm})$ & $3.0 \pm 0.5$ & $3.1 \pm 1.0$ & $3.1 \pm 0.9$ & 0.855 \\
\hline Stent length $(\mathrm{mm})$ & $20.2 \pm 6.8$ & $20.0 \pm 7.4$ & $19.5 \pm 6.4$ & 0.247 \\
\hline IABP $(\%)$ & 5.5 & 6.1 & 2.9 & 0.001 \\
\hline Cardiac arrest (\%) & 0.7 & 0.8 & 0.8 & 0.728 \\
\hline Arrhythmias (\%) & 8.0 & 7.1 & 6.8 & 0.771 \\
\hline Vascular complications (\%) & 1.2 & 0.9 & 0.6 & 0.480 \\
\hline 30-day TIMI major bleeding (\%) & 0.9 & 0.9 & 0.8 & 0.829 \\
\hline 30-day TIMI minor bleeding (\%) & 2.1 & 2.0 & 1.8 & 0.121 \\
\hline Acute kidney injury (\%) & 12.9 & 9.1 & 8.8 & 0.093 \\
\hline Median admission length (IQR) & $4.1(1.8-6.9)$ & $4.1(1.6-7.2)$ & $3.9(1.1-5.4)$ & 0.127 \\
\hline Aspirin $(\%)$ & 90.7 & 90.3 & 92.8 & 0.107 \\
\hline Ticagrelor $(\%)$ & 9.9 & 5.5 & 4.2 & 0.132 \\
\hline Clopidogrel (\%) & 55.8 & 48.7 & 14.8 & 0.039 \\
\hline Prasugrel $(\%)$ & 3.8 & 42.1 & 79.5 & $<0.001$ \\
\hline Statins (\%) & 94.5 & 96.5 & 97.2 & 0.192 \\
\hline Beta-blockers (\%) & 72.2 & 68.2 & 67.3 & 0.113 \\
\hline ACE inhibitors (\%) & 66.3 & 65.8 & 62.1 & 0.005 \\
\hline
\end{tabular}

IQR —interquartile range, IABP—intra-aortic balloon pump, DES—drug eluting stents, TIMI—-thrombolysis in myocardial infarction.

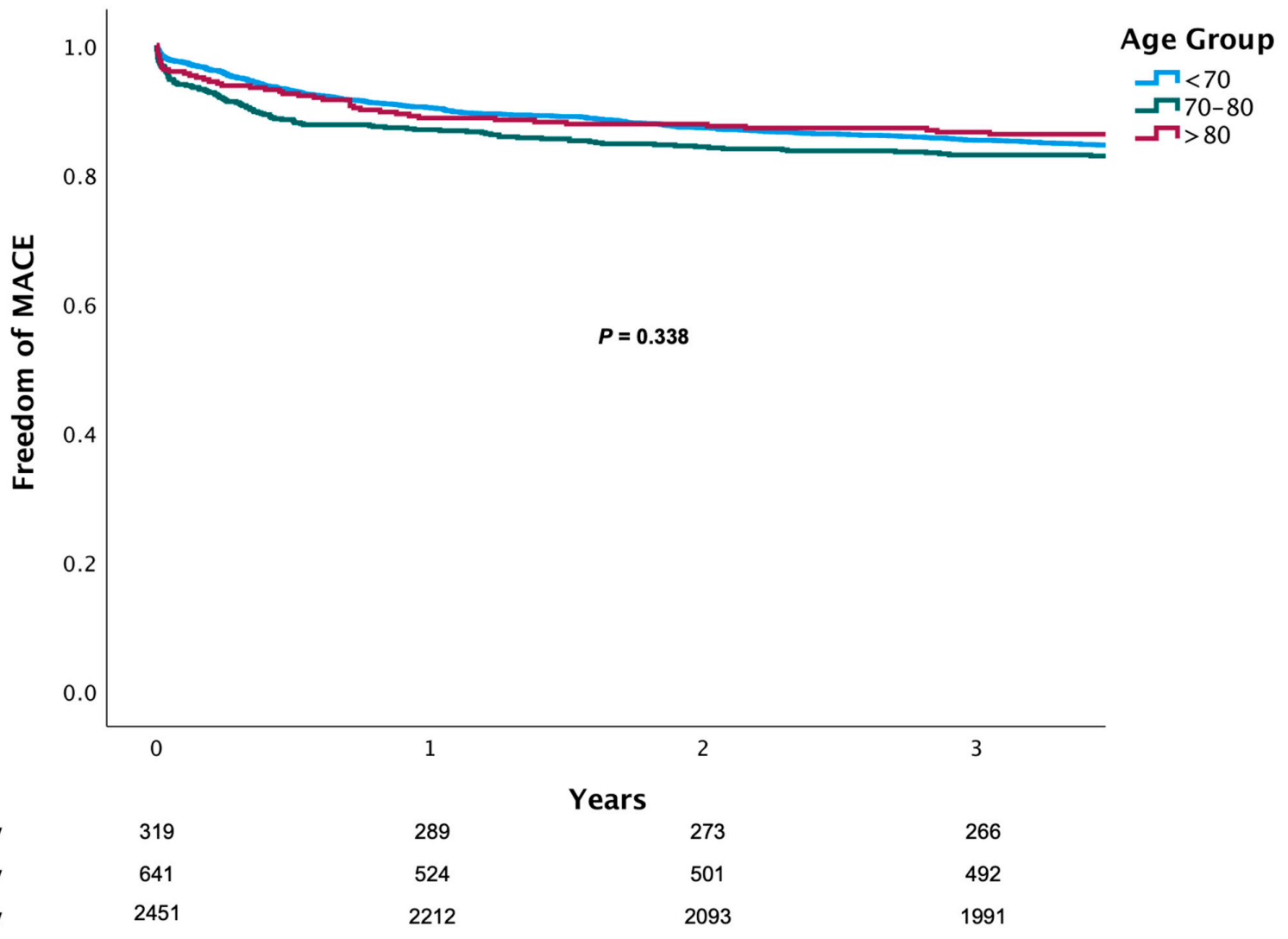

Figure 2. Kaplan-Meier curve of MACE according to age. 

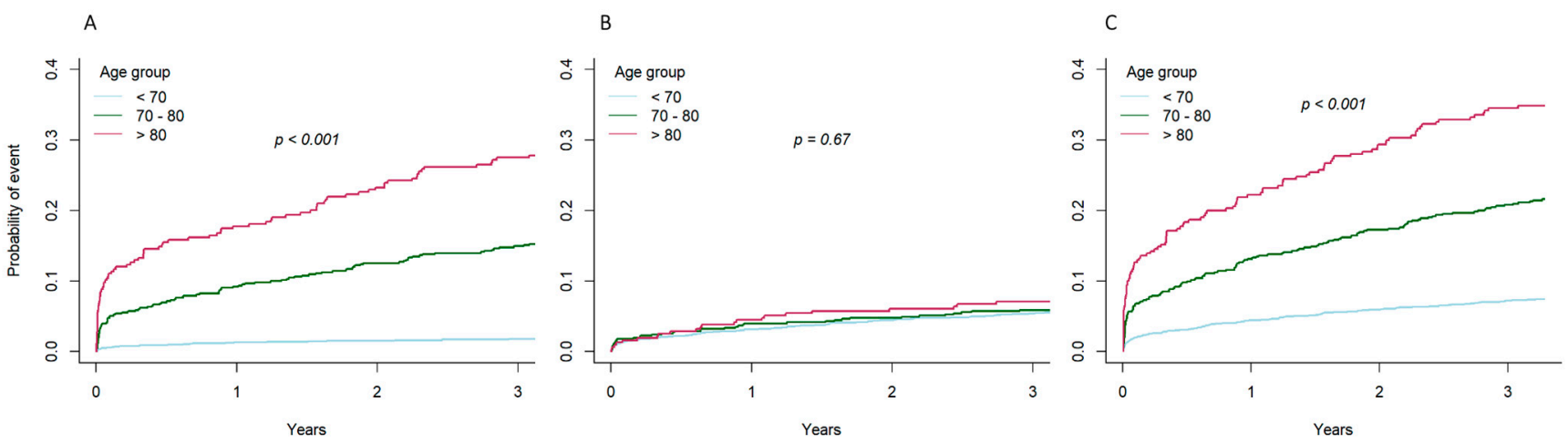

Figure 3. Cumulative incidence function of death according to age. (A) Probability of noncardiovascular death; (B) probability of cardiovascular death; (C) probability of all-cause death.

Univariate analysis identified the following predictors of 30-day and 3-year mortality after STEMI: age over 80, previous PCI, previous MI, previous CABG surgery, diabetes mellitus, hypertension, hyperlipidemia, renal failure, LVEF, the implantation of DES, and intra-aortic balloon pump (Table $3 a, b)$. We used these factors, including age, gender, and the administration of Prasugrel as opposed to clopidogrel for the multivariate analysis. On regression analysis (Table $4 a, b)$, factors significantly related to an increased risk of death at 1 month were age over 80 years (HR 1.88; 95\% CI 1.02-4.78, $p=0.041$ ), diabetes mellitus (HR 1.97; 1.04-3.72, $p=0.038$ ), renal failure (HR 2.02; 1.08-3.80, $p=0.029$ ), reduced leftventricular ejection fraction (HR $0.93 ; 0.90-0.95$ for each additional $1 \%$ in ejection fraction, $p<0.001$ ), and the use of intra-aortic balloon pump (HR 1.79; 1.02-4.21, $p=0.032$, Table 3a). At 3 years, the parameters significantly related to all-cause death were age group (HR 3.89; 2.74-5.52 for octogenarians, and 3.19; 2.33-4.36 for septuagenarians, $p<0.001$ for both), diabetes mellitus (HR 1.41; 1.06-1.85, $p=0.016$ ), renal failure (HR 2.44; 1.82-3.28, $p<0.001$ ), left-ventricular ejection fraction (HR 0.94; 0.92-0.97, $p<0.001$ ), and the implantation of drug-eluting stents (HR 0.66; 0.48-0.89, $p=0.008$, Table 3b). The 30-day MACE was also assessed in regression analysis, demonstrating an increase in risk for events for patients with previous PCI (HR 1.42; 1.01-2.67, $p=0.042$ ), diabetes mellitus (HR 2.45; 1.43-4.37, $p=0.021$ ), and renal failure at baseline (HR 2.21; 1.23-4.98, $p=0.008$ ). Age was not an independent predictor of 30-day MACE. A test for interaction of the individual medical center and outcomes yielded no significant results.

Table 3. (a) Univariate analysis of 30-day mortality predictors. (b) Cox regression analysis of 3-year mortality predictors.

\begin{tabular}{ccccc}
\hline Parameters & Hazard Ratio & Lower & Upper & $p$-Value \\
\hline & $(\mathbf{a})$ & & & \\
\hline Age group 70-80 & 1.38 & 0.93 & 2.34 & 0.261 \\
Age group >80 & 1.57 & 1.07 & 4.11 & 0.002 \\
Gender (female) & 1.24 & 0.82 & 1.45 & 0.338 \\
Previous PCI * & 1.32 & 1.20 & 4.51 & 0.002 \\
Previous myocardial infarction & 1.09 & 1.00 & 1.92 & 0.080 \\
CABG ** & 1.66 & 1.34 & 4.92 & 0.040 \\
T2DM II $_{\text {Hypertension }}$ & 1.49 & 1.02 & 3.98 & 0.021 \\
Hyperlipidemia & 1.09 & 1.01 & 2.02 & 0.092 \\
Renal failure & 1.20 & 1.03 & 2.98 & 0.004 \\
LVEF II (additional 1\%) & 2.73 & 1.45 & 4.98 & 0.007 \\
DES \# & 0.91 & 0.67 & 0.98 & $<0.001$ \\
Prasugrel & 0.67 & 0.38 & 1.95 & 0.082 \\
IABP *** & 0.76 & 0.46 & 1.19 & 0.121 \\
& 1.82 & 1.02 & 3.75 & 0.040 \\
\hline
\end{tabular}


Table 3. Cont.

\begin{tabular}{ccccc}
\hline Parameters & Hazard Ratio & Lower & Upper & $p$-Value \\
\hline & $(\mathbf{b})$ & & & \\
\hline Age group 70-80 & 1.97 & 0.89 & 5.31 & 0.110 \\
Age group >80 & 3.62 & 1.83 & 6.23 & $<.001$ \\
Gender (female) & 1.35 & 0.90 & 1.83 & 0.119 \\
Previous PCI * & 1.32 & 0.99 & 1.81 & 0.094 \\
Previous myocardial infarction & 1.42 & 1.02 & 2.32 & 0.083 \\
CABG $^{* *}$ & 1.58 & 1.11 & 3.94 & 0.067 \\
T2DM $^{\text {|l }}$ & 1.62 & 1.06 & 4.29 & 0.006 \\
Hypertension & 1.08 & 0.97 & 4.01 & 0.072 \\
Hyperlipidemia & 1.23 & 1.00 & 3.29 & 0.100 \\
Renal failure & 2.67 & 1.63 & 5.29 & $<0.001$ \\
LVEF II (additional 1\%) $_{\text {DES }}^{\#}$ & 0.91 & 0.82 & 0.97 & $<0.001$ \\
Prasugrel $_{\text {IABP }}^{* * *}$ & 0.62 & 0.41 & 0.93 & 0.006 \\
\hline
\end{tabular}

* PCI—percutaneous coronary intervention, ${ }^{* *} \mathrm{CABG}$ - coronary artery bypass graft surgery, ${ }^{11}$ T2DM-type 2 diabetes mellitus, II LVEF-left ventricular ejection fraction, ${ }^{\#}$ DES-drug-eluting stent, ${ }^{* * *}$ IABP-intra-aortic balloon pump.

Table 4. (a) Cox regression analysis of 30-day mortality predictors. (b) Cox regression analysis of 3-year mortality predictors.

\begin{tabular}{|c|c|c|c|c|}
\hline Parameters & Hazard Ratio & Lower & Upper & $p$-Value \\
\hline \multicolumn{5}{|c|}{ (a) } \\
\hline Age group 70-80 & 1.52 & 0.84 & 2.73 & 0.371 \\
\hline Age group > 80 & 1.88 & 1.02 & 4.78 & 0.041 \\
\hline Gender (female) & 1.29 & 0.96 & 1.81 & 0.255 \\
\hline Previous PCI* & 0.93 & 0.39 & 2.20 & 0.871 \\
\hline Previous myocardial infarction & 0.62 & 0.24 & 1.64 & 0.338 \\
\hline $\mathrm{CABG}^{* *}$ & 1.66 & 0.56 & 4.97 & 0.364 \\
\hline $\mathrm{T} 2 \mathrm{DM}||$ & 1.97 & 1.04 & 3.72 & 0.038 \\
\hline Hypertension & 0.97 & 0.48 & 1.94 & 0.926 \\
\hline Hyperlipidemia & 1.10 & 0.57 & 2.13 & 0.778 \\
\hline Renal failure & 2.02 & 1.08 & 3.80 & 0.029 \\
\hline LVEF II (additional 1\%) & 0.93 & 0.89 & 0.95 & $<0.001$ \\
\hline DES \# & 0.55 & 0.26 & 1.17 & 0.119 \\
\hline Prasugrel & 0.78 & 0.42 & 1.82 & 0.729 \\
\hline $\operatorname{IABP} * * *$ & 1.79 & 1.02 & 4.21 & 0.032 \\
\hline \multicolumn{5}{|c|}{ (b) } \\
\hline Age group 70-80 & 3.19 & 2.33 & 4.36 & $<0.001$ \\
\hline Age group > 80 & 3.89 & 2.74 & 5.52 & $<0.001$ \\
\hline Gender (female) & 1.24 & 0.94 & 1.65 & 0.127 \\
\hline Previous PCI * & 1.13 & 0.77 & 1.67 & 0.524 \\
\hline Previous myocardial infarction & 1.32 & 0.41 & 1.98 & 0.156 \\
\hline $\mathrm{CABG}^{* *}$ & 1.53 & 0.91 & 2.56 & 0.111 \\
\hline $\mathrm{T} 2 \mathrm{DM}||$ & 1.41 & 1.06 & 1.85 & 0.016 \\
\hline Hypertension & 1.03 & 0.76 & 1.39 & 0.851 \\
\hline Hyperlipidemia & 1.18 & 0.89 & 1.55 & 0.245 \\
\hline Renal failure & 2.44 & 1.82 & 3.28 & $<0.001$ \\
\hline LVEF II (additional 1\%) & 0.94 & 0.92 & 0.97 & $<0.001$ \\
\hline DES \# & 0.66 & 0.48 & 0.89 & 0.008 \\
\hline Prasugrel & 0.75 & 0.49 & 1.27 & 0.371 \\
\hline $\mathrm{IABP} * * *$ & 1.72 & 0.82 & 9.31 & 0.821 \\
\hline
\end{tabular}

* PCI—percutaneous coronary intervention, ${ }^{* *} \mathrm{CABG}$ - coronary artery bypass graft surgery, ${ }^{11}$ T2DM-type 2 diabetes mellitus, ${ }^{\text {II }} \mathrm{LVEF}$ - left ventricular ejection fraction, ${ }^{\#}$ DES - drug-eluting stent, ${ }^{* * *}$ IABP-intra-aortic balloon pump. 


\section{Discussion}

Our study encompassed the experience of two Mediterranean-area tertiary medical centers with PPCI for the treatment of STEMI in the elderly. Compared to septuagenarians, octogenarians had a higher rate of all-cause mortality but similar rates of cardiac death, cardiac ischemic endpoints, and MACE.

There is relatively little information regarding the outcomes of octogenarians undergoing pPCI. Most of the evidence is derived from single-center observational studies. An early single-center study from the Netherlands that examined the outcomes of 4506 patients with STEMI reported a very high 1-year mortality rate (28.2\%) in the octogenarian group $(n=379)$ [7]. Another, from Canada [5], compared 164 octogenarians with patients 65-69 years old and found that the octogenarian group was more likely to have a delay in treatment, increased rates of bleeding, acute kidney injury, and rehospitalization, and a trend toward longer hospital stay following pPCI. Their overall survival after 12 months was significantly lower than the control value ( $79 \%$ vs. $94 \%, p<0.01)$. An additional study based on the Korean Acute Myocardial Infarction Registry (KAMIR) reported a significantly higher 12-month all-cause mortality rate in octogenarians than in nonoctogenarians $(22.3 \%$ vs. $6.5 \%, p<0.001$ ) [11]. Additionally, a separate report based on the KAMIR registry demonstrated an incremental relationship with MACE. [28] However, two observational studies from China $[20,29]$ showed that in elderly patients with STEMI, early reperfusion, especially with pPCI, was safe and effective compared with no reperfusion. Regarding the type of reperfusion, one of these studies assessed the use of fibrinolytic therapy in elderly patients with STEMI, with or without PCI, and found that it was associated with an eightfold increase in hemorrhagic stroke with no mortality benefit [22].

Our study is in good agreement with previous reports in terms of elevated all-cause death rates for the octogenarian group, reaching about $20 \%$ after 12 months. However, our experience shows that in survivors, the rates of other outcomes related to ischemic cardiac events, such as TVR, recurrent MI, and cardiac death, are similar between octogenarians and controls a decade younger. These findings partially contrast with the study from Korea, which suggested that age was incrementally related to MACE and cardiac death, although not to TVR [28]. Yet, they are in line with the separate analysis from the same registry, which found that octogenarian patients with acute MI had higher rates of mortality than nonoctogenarians, with no difference in rates of target lesion revascularization, TVR, recurrent acute $\mathrm{MI}$, and CABG [11].

A higher rate of all-cause mortality is expected in the octogenarian and septuagenarian populations. We therefore assessed cardiovascular ischemic outcomes as well, such as cardiovascular death, TVR, recurrent MI, and CABG. It is important to mention that some of these outcomes may be influenced by the cardiac team's preference of therapy (for example, rates of TVR or CABG may be somewhat lower in the very elderly patient population due to the higher perceived risk of the procedure). Nevertheless, the observation that other "hard" end points, such as cardiac death and MI, occurred at similar rates to controls, suggests similar benefits for PPCI for STEMI in the elderly. Hence, this study reinforces the present guidelines for the assessment and treatment of older patients with STEMI; namely, use of a similar approach to that applied in the general population in terms of timely revascularization preferably by pPCI when feasible $[23,24]$. At the same time, our study highlights the need for global evaluation of elderly patients with STEMI in order to correctly understand their prognosis, especially in cases in which survival appears to be influenced by noncardiologic conditions such as malignancies and neurological and degenerative diseases [13].

Regarding adjunctive therapy, some studies support a short duration of dual antiplatelet therapy for elderly patients treated by PCI due to a higher risk of bleeding [30,31]. All patients in our cohort were advised to continue with dual antiplatelet therapy for at least 12 months. This may have reduced the rate of ischemic outcomes in our study, while surprisingly not significantly raising the rate of bleeding in the octogenarians relative to the septuagenarians. The longstanding debate regarding the length of dual antiplatelet 
therapy in this patient population persists, although at least in patients with STEMI, our study adds evidence for the benefit of a 12-month-long treatment regimen in preventing recurrent ischemic events.

We opted to report on patients in the eighth and ninth decade of their lives. However, as the population ages, more nonagenarians and even centenarians may be considered for revascularization. There is already some evidence to support invasive therapy in these age groups, although the mortality rate is higher, even when compared with octogenarians [19,32]. In the future, studies assessing outcomes, as well as the preferred mode of both invasive and medical therapy for these patients, will shed more light on this growing patient population.

\section{Limitations}

The observational design of this study, as well as the arbitrary choice of the age of the control group, precludes speculations regarding ways to improve the prognosis of elderly patients treated with PPCI for STEMI. As such, we cannot rule out significant selection bias of both the study and control groups. A randomized controlled study comparing pPCI with conservative therapy in two similar elderly cohorts would more appropriately assess the true impact of revascularization in this patient population. However, at the present time, such a study design is likely to be considered unethical. In addition, we had information on whether the cause of death was cardiac or noncardiac, but specific details were missing. Therefore, the exact causes of the relatively high case-fatality rates in the octogenarians are not well defined. Despite these limitations, this study is one of the largest on elderly patients with STEMI treated by pPCI, derived from two tertiary medical centers, and it sheds important light on the prognosis of this growing patient population.

\section{Conclusions}

Patients more than 70 years old with STEMI who are treated by pPCI suffer from higher rates of all-cause death but similar rates of ischemic cardiac events, including cardiovascular death, TVR, recurrent MI, and CABG. These data support the importance of pPCI in cases of STEMI in the elderly population. Although future prospective trials assessing the efficacy of $\mathrm{pPCI}$ in the elderly population suffering from STEMI may presently be considered unethical, studies examining aspects of specific device and medical treatment modalities for this unique group of patients are warranted.

Author Contributions: Conceptualization, L.P., F.D., G.M.D.F. and R.K.; Data curation, L.P., A.F. N.G. and G.G.; Investigation, L.P., A.F., N.G., A.L., F.D. and A.A.; Resources, H.V.-A. and G.G.; Supervision, F.D., A.A. and R.K.; Writing—original draft, L.P.; Writing—review \& editing, L.P., G.M.D.F. and R.K.. All authors have read and agreed to the published version of the manuscript.

Funding: There are no external sources of funding to be reported.

Institutional Review Board Statement: The study was approved by the Institutional Review Boards of the two participating centers (study number RMC-3741 at the Rabin Medical Center and study number 0119191 at the Department of Medical Sciences, University of Turin).

Informed Consent Statement: All patients provided explicit written informed consent before undergoing cardiac catheterization.

Data Availability Statement: Anonymized study data can be requested by contacting Leor Perl (leorperl@gmail.com).

Conflicts of Interest: We declare that all authors have no relevant conflicts of interest for this study. 


\section{References}

1. Mozaffarian, D.; Benjamin, E.J.; Go, A.S.; Arnett, D.K.; Blaha, M.J.; Cushman, M.; Das, S.R.; de Ferranti, S.; Després, J.-P.; Fullerton, H.J.; et al. Heart Disease and Stroke Statistics-2016 Update: A Report From the American Heart Association. Circulation 2016, 133, e38-e360. [CrossRef]

2. Barbero, U.; Scacciatella, P.; Iannaccone, M.; D’Ascenzo, F.; Niccoli, G.; Colombo, F.; Ugo, F.; Colangelo, S.; Mancone, M.; Calcagno, S.; et al. Culprit plaque characteristics in younger versus older patients with acute coronary syndromes: An optical coherence tomography study from the FORMIDABLE registry. Catheter. Cardiovasc. Interv. 2018, 92, E1-E8. [CrossRef]

3. Goff, D.C.; Lloyd-Jones, D.M.; Bennett, G.; Coady, S.; D’Agostino, R.B.; Gibbons, R.; Greenland, P.; Lackland, D.T.; Levy, D.; O'Donnell, C.J.; et al. 2013 ACC/AHA Guideline on the Assessment of Cardiovascular Risk: A Report of the American College of Cardiology/American Heart Association Task Force on Practice Guidelines. J. Am. Coll. Cardiol. 2014, 63, 2935-2959. [CrossRef] [PubMed]

4. Appleby, C.E.; Ivanov, J.; Mackie, K.; Džavík, V.; Overgaard, C.B. In-hospital outcomes of very elderly patients (85 years and older) undergoing percutaneous coronary intervention. Catheter. Cardiovasc. Interv. 2011, 77, 634-641. [CrossRef] [PubMed]

5. Sharma, R.; Hiebert, B.; Cheung, D.; Jassal, D.S.; Minhas, K. Primary Coronary Intervention in Octogenarians and Nonagenarians With ST-Segment Elevation Myocardial Infarction: A Canadian Single-Center Perspective. Angiology 2018, 69, 718-723. [CrossRef]

6. Velásquez-Rodríguez, J.; Diez-Delhoyo, F.; Valero-Masa, M.J.; Vicent, L.; Devesa, C.; Sousa-Casasnovas, I.; Juárez, M.; AnguloLlanos, R.; Fernández-Avilés, F.; Martínez-Sellés, M. Prognostic Impact of Age and Hemoglobin in Acute ST-Segment Elevation Myocardial Infarction Treated With Reperfusion Therapy. Am. J. Cardiol. 2017, 119, 1909-1916. [CrossRef] [PubMed]

7. Claessen, B.E.P.M.; Kikkert, W.J.; Engstrom, A.E.; Hoebers, L.P.C.; Damman, P.; Vis, M.M.; Koch, K.T.; Baan, J.; Meuwissen, M.; J van der Schaaf, R.; et al. Primary percutaneous coronary intervention for ST elevation myocardial infarction in octogenarians: Trends and outcomes. Heart 2010, 96, 843-847. [CrossRef]

8. Vandecasteele, E.H.; De Buyzere, M.; Gevaert, S.; de Meester, A.; Convens, C.; Dubois, P.; Boland, J.; Sinnaeve, P.; De Raedt, H.; Vranckx, P.; et al. Reperfusion therapy and mortality in octogenarian STEMI patients: Results from the Belgian STEMI registry. Clin. Res. Cardiol. 2013, 102, 837-845. [CrossRef]

9. Sappa, R.; Grillo, M.T.; Cinquetti, M.; Prati, G.; Spedicato, L.; Nucifora, G.; Perkan, A.; Zanuttini, D.; Sinagra, G.; Proclemer, A. Short and long-term outcome in very old patients with ST-elevation myocardial infarction after primary percutaneous coronary intervention. Int. J. Cardiol. 2017, 249, 112-118. [CrossRef]

10. Qaderdan, K.; Vos, G.-J.A.; McAndrew, T.; Steg, P.G.; Hamm, C.W.; Van't Hof, A.; Mehran, R.; Deliargyris, E.N.; Bernstein, D.; Stone, G.W.; et al. Outcomes in elderly and young patients with ST-segment elevation myocardial infarction undergoing primary percutaneous coronary intervention with bivalirudin versus heparin: Pooled analysis from the EUROMAX and HORIZONS-AMI trials. Am. Heart J. 2017, 194, 73-82. [CrossRef]

11. Yamanaka, F.; Jeong, M.H.; Saito, S.; Ahn, Y.; Chae, S.C.; Hur, S.H.; Hong, T.J.; Kim, Y.J.; Seong, I.W.; Chae, J.K.; et al. Comparison of clinical outcomes between octogenarians and non-octogenarians with acute myocardial infarction in the drug-eluting stent era: Analysis of the Korean Acute Myocardial Infarction Registry. J. Cardiol. 2013, 62, 210-216. [CrossRef]

12. Chen, P.-F.; Wang, D.-N.; Chen, K.; Liang, C.; Reng, Y.-S.; Yang, J.; Ding, R.; Blackwell, J.; Liao, D.-N. Outcomes of percutaneous coronary intervention in patients $\geq 75$ years: One-center study in a Chinese patient group. J. Geriatr. Cardiol. 2015, 12, 626-633. [CrossRef]

13. Moretti, C.; Quadri, G.; D’Ascenzo, F.; Bertaina, M.; Giusto, F.; Marra, S.; Moiraghi, C.; Scaglione, L.; Torchio, M.; Montrucchio, G.; et al. THE STORM (acute coronary Syndrome in paTients end Of life and Risk assesMent) study. Emerg. Med. J. 2016, 33, 10-16. [CrossRef]

14. Goff, D.C.; Feldman, H.A.; McGovern, P.G.; Goldberg, R.J.; Simons-Morton, D.G.; Cornell, C.E.; Osganian, S.K.; Cooper, L.S.; Hedges, J.R. Prehospital delay in patients hospitalized with heart attack symptoms in the United States: The REACT trial. Rapid Early Action for Coronary Treatment (REACT) Study Group. Am. Heart J. 1999, 138, 1046-1057. [CrossRef]

15. Goldberg, R.J.; Steg, P.G.; Sadiq, I.; Granger, C.B.; Jackson, E.A.; Budaj, A.; Brieger, D.; Avezum, A.; Goodman, S. Extent of, and factors associated with, delay to hospital presentation in patients with acute coronary disease (the GRACE registry). Am. J. Cardiol. 2002, 89, 791-796. [CrossRef]

16. Bueno, H.; Betriu, A.; Heras, M.; Alonso, J.J.; Cequier, A.; García, E.J.; López-Sendón, J.L.; Macaya, C.; Hernández-Antolín, R.; TRIANA Investigators. Primary angioplasty vs. fibrinolysis in very old patients with acute myocardial infarction: TRIANA (TRatamiento del Infarto Agudo de miocardio eN Ancianos) randomized trial and pooled analysis with previous studies. Eur. Heart J. 2011, 32, 51-60. [CrossRef] [PubMed]

17. Yudi, M.B.; Jones, N.; Fernando, D.; Clark, D.J.; Ramchand, J.; Jones, E.; Dakis, R.; Johnson, D.; Chan, R.; Islam, A.; et al. Management of patients aged $\geq 85$ years with ST-elevation myocardial infarction. Am. J. Cardiol. 2016, 118, 44-48. [CrossRef] [PubMed]

18. Couture, E.L.; Farand, P.; Nguyen, M.; Allard, C.; Wells, G.A.; Mansour, S.; Rinfret, S.; Afilalo, J.; Eisenberg, M.; Montigny, M.; et al. Impact of an invasive strategy in the elderly hospitalized with acute coronary syndrome with emphasis on the nonagenarians. Catheter Cardiovasc Interv. 2018, 92, E441. [CrossRef] [PubMed]

19. Teplitsky, I.; Assali, A.; Lev, E.; Brosh, D.; Vaknin-Assa, H.; Kornowski, R. Results of percutaneous coronary interventions in patients $>$ or $=90$ years of age. Catheter Cardiovasc Interv. 2007, 70, 937-943. [CrossRef] 
20. Peiyuan, H.; Jingang, Y.; Haiyan, X.; Xiaojin, G.; Ying, X.; Yuan, W.; Wei, L.; Yang, W.; Xinran, T.; Ruohua, Y.; et al. The comparison of the outcomes between primary PCI, fibrinolysis, and no reperfusion in patients $\geq 75$ years old with ST-segment elevation myocardial infarction: Results from the Chinese Acute Myocardial Infarction (CAMI) Registry. PLoS ONE 2016, 11, e0165672. [CrossRef] [PubMed]

21. Le May, M.R.; Labinaz, M.; Davies, R.F.; Marquis, J.F.; Laramée, L.A.; O’Brien, E.R.; Williams, W.L.; Beanlands, R.S.; Nichol, G.; Higginson, L.A. Stenting versus thrombolysis in acute myocardial infarction trial (STAT). J. Am. Coll. Cardiol. 2001, 37, 985-991. [CrossRef]

22. Ogunbayo, G.O.; Misumida, N.; Ayoub, K.; Hailemariam, Y.; Hillerson, D.; Elbadawi, A.; Abdel-Latif, A.; Smyth, S.; Ziada, K.; Messerli, A.W. Temporal trends, characteristics and outcomes of fibrinolytic therapy for ST-elevation myocardial infarction among patients 80 years or older. Catheter Cardiovasc Interv. 2018, 92, E425-E432. [CrossRef] [PubMed]

23. O'Gara, P.T.; Kushner, F.G.; Ascheim, D.D.; Casey, D.E.; Chung, M.K.; de Lemos, J.A.; Ettinger, S.M.; Fang, J.C.; Fesmire, F.M.; Franklin, B.A.; et al. 2013 ACCF/AHA guideline for the management of ST-elevation myocardial infarction: A report of the American College of Cardiology Foundation/American Heart Association Task Force on Practice Guidelines. Circulation 2013, 127, e362-e425. [CrossRef] [PubMed]

24. Ibanez, B.; James, S.; Agewall, S.; Antunes, M.J.; Bucciarelli-Ducci, C.; Bueno, H.; Caforio, A.L.P.; Crea, F.; Goudevenos, J.A.; Halvorsen, S.; et al. 2017 ESC Guidelines for the management of acute myocardial infarction in patients presenting with STsegment elevationThe Task Force for the management of acute myocardial infarction in patients presenting with ST-segment elevation of the European Society of Cardiology (ESC). Eur. Heart J. 2018, 39, 119-177. [PubMed]

25. Madhavan, M.V.; Gersh, B.J.; Alexander, K.P.; Granger, C.B.; Stone, G.W. Coronary Artery Disease in Patients $\geq 80$ Years of Age. J. Am. Coll. Cardiol. 2018, 71, 2015-2040. [CrossRef]

26. Lee, P.Y.; Alexander, K.P.; Hammill, B.G.; Pasquali, S.K.; Peterson, E.D. Representation of elderly persons and women in published randomized trials of acute coronary syndromes. JAMA 2001, 286, 708-713. [CrossRef]

27. Jinatongthai, P.; Kongwatcharapong, J.; Foo, C.Y.; Phrommintikul, A.; Nathisuwan, S.; Thakkinstian, A.; Reid, C.M.; Chaiyakunapruk, N. Comparative efficacy and safety of reperfusion therapy with fibrinolytic agents in patients with ST-segment elevation myocardial infarction: A systematic review and network meta-analysis. Lancet. 2017, 390, 747-759. [CrossRef]

28. Kim, D.-W.; Her, S.-H.; Park, H.W.; Chang, K.; Chung, W.S.; Seung, K.B.; Jeong, M.H.; Kim, H.-S.; Gwon, H.C.; Seong, I.W.; et al. Incremental age-related one-year MACCE after acute myocardial infarction in the drug-eluting stent era (from KAMIR-NIH registry). J. Geriatr. Cardiol. 2018, 15, 574-584.

29. Liu, S.L.; Wu, N.Q.; Zhang, M.; Jin, J.L.; Zhou, B.Y.; Dong, Q.; Li, J.J. Association of invasive treatment and lower mortality of patients $\geq 80$ years with acute myocardial infarction: A propensity-matched analysis. J. Geriatr. Cardiol. 2018, 15, 666-674.

30. Costa, F.; van Klaveren, D.; James, S.; Heg, D.; Räber, L.; Feres, F.; Pilgrim, T.; Hong, M.-K.; Kim, H.-S.; Colombo, A.; et al. Derivation and validation of the predicting bleeding complications in patients undergoing stent implantation and subsequent dual antiplatelet therapy (PRECISE-DAPT) score: A pooled analysis of individual-patient datasets from clinical trials. Lancet 2017, 389, 1025-1034. [CrossRef]

31. Varenne, O.; Cook, S.; Sideris, G.; Kedev, S.; Cuisset, T.; Carrié, D.; Hovasse, T.; Garot, P.; El Mahmoud, R.; Spaulding, C.; et al. Drug-eluting stents in elderly patients with coronary artery disease (SENIOR): A randomised single-blind trial. Lancet 2018, 391, 41-50. [CrossRef]

32. Lee, K.H.; Ahn, Y.; Kim, S.S.; Rhew, S.H.; Jeong, Y.W.; Jang, S.Y.; Cho, J.Y.; Jeong, H.C.; Park, K.-H.; Yoon, N.S.; et al. Characteristics, in-hospital and long-term clinical outcomes of nonagenarian compared with octogenarian acute myocardial infarction patients. $J$. Korean Med. Sci. 2014, 29, 527-535. [CrossRef] [PubMed] 